\title{
ENTREVISTA COM ROSANA PAULINO
}

Rosana Paulino

Doutora em Poéticas Visuais pela Escola de Comunicações e Artes da Universidade de São Paulo - ECA/USP (2011), na modalidade DD - Doutorado Direto - sob orientação do Professor Evandro Carlos Jardim. Possui graduação em Artes Plásticas pela Universidade de São Paulo (1995) e é especialista em Gravura pelo London Print Studio, de Londres (1998). Como artista, participou de várias exposições no Brasil e no exterior. Foi bolsista do Bellagio Center, da Fundação Rockefeller (2014), do Programa Internacional de Bolsas de Pós-Graduação da Fundação Ford (2006/2008) e da CAPES (2008/2011) para obtenção do título de Doutora. Participou de estágio no Tamarind Institute, da New México University, na área de Gravura (litografia) no ano de 2012 .

Fonte: http://lattes.cnpq.br/8080222583272953

Entrevista realizada pelo estúdio de pintura apotheke, com referência no livro de Joe Fig, Inside The Painter's Studio (Princeton Architectural Press, 2009) ${ }^{1}$.

\section{QUESTIONÁRIO J. FIG}

1 - Quando que você se considerou um artista profissional, e quando se sentiu capaz de dedicar-se em tempo integral à arte?

Rosana Paulino [R.P.] Esta é uma pergunta difícil, porque o que é ser um artista profissional no Brasil? Tem muita gente que faz um trabalho ruim, mas vende muito, ou seja, é profissional, mas o trabalho é relevante? E tem gente que tem um ótimo trabalho, no entanto não é devidamente reconhecido, tem que fazer loucuras para sobreviver. Portanto, diante do panorama, nem sei se me considero uma artista profissional porque dependo de aulas e outras atividades para manter o ateliê, embora não considere, em 


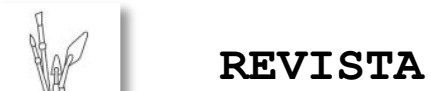 \\ A) APOPHEKE}

hipótese alguma, lecionar uma atividade menor. Dar aulas é uma das minhas paixões. Mas, por outro lado, temos o fator da escolha, ainda não posso escolher ser somente artista, não tenho como abrir mão das aulas, palestras, oficinas, etc. Porque não conseguiria fechar o mês. Digamos, então, que posso me considerar uma artista profissional pela relevância que o trabalho alcançou, mas, por outro lado, não sou profissional no sentido de viver só de minhas obras. Porém, com certeza, sei que consigo despender mais tempo na produção da minha obra do que a média daqueles que se dedicam à produção artística.

E em relação a sua produção artística, quanto tempo você tem estado em estúdio?

Não costumo medir isso porque é uma medida muito relativa. Tem trabalhos nos quais eu preciso ficar mais tempo fora, pensando, pesquisando e/ou visitando museus, por exemplo. Outros exigem que eu esteja mais tempo trabalhando na prensa. E as vezes surge também uma viagem de pesquisa, que também é trabalho, faz com que no meu retorno a produção renda mais e se desenvolva com maior facilidade. O trabalho não acontece só no ateliê, como dá para perceber pelos exemplos acima. Não tenho uma medida específica de quanto tempo eu gasto no estúdio, é difícil quantificar.

2 - Quando você começou a trabalhar neste espaço?

[R.P.] Em 1999. Já estava pronto em 98, mas neste ano estive na Inglaterra para fazer minha especialização em gravura e o ateliê ficou fechado.

3 - A localização do seu estúdio influenciou seu trabalho de alguma forma?

[R.P.] Se pensarmos localização apenas como o espaço geográfico da cidade onde habito, no caso São Paulo, a 


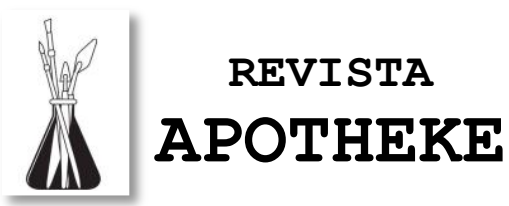

localização do ateliê facilita muito o trabalho, mas não influencia. Facilita porque como construí no terreno da casa dos meus pais, e não desfiz meu quarto lá, posso trabalhar nos horários mais inusitados fazendo barulho (o terreno ao redor é bem grande e não incomoda as casas vizinhas ou a casa deles) e sem ter a preocupação de ter que voltar para casa. Simplesmente durmo por lá. Não gosto de dormir dentro do ateliê, preciso de um espaço separado senão fico com a impressão de que não descansei. Ter um quarto em outro local, que não seja dentro do ateliê, funciona bem para mim.

Talvez a pergunta deva ser feita de outra forma: estar em um determinado país influencia a obra? Neste caso a resposta é positiva. Quando morei na Inglaterra meu trabalho mudou muito e este foi um dos motivos pelos quais voltei ao Brasil, apesar da insistência deles de que permanecesse por lá.

4 - Você pode descrever um dia típico em sua vida?

[R.P.] Impossível, porque não tenho rotina. Aliás, detesto rotina! Meu dia varia conforme meu trabalho. Tem dias que fico resolvendo assuntos "de escritório", fazendo projetos, preparando aulas, nem chego perto da parte prática do ateliê. Em outros vou direto para lá. Depende de vários fatores: humor, prazos, viagens, necessidade de fechamento de uma exposição...

5 - Você costuma ouvir música, rádio, TV quando está trabalhando, e isso afeta o seu trabalho?

[R.P.] Não trabalho sem música. Posso até trabalhar com pouco material se estiver faltando, mas sem música nunca! E a música afeta de modo positivo meu trabalho. Em alguns momentos, se estou procurando um clima tenso para uma obra 


\section{\)}

ponho uma música que me leve a este estado de tensão. Em outros, quando estou imprimindo, coloco uma boa MPB. Quando estou lendo prefiro o silêncio, mas quando estou desenhando, por exemplo, tem que ter música.

6 - Que tipo de tintas que você usa?

[R.P.] Basicamente tintas para gravura, aquarela ou acrílica no caso dos desenhos.

7 - Poderias me falar um pouco sobre suas paletas de pintura?

[R.P.] Bem, não sou pintora e sim artista multimídia. Então acho que esta pergunta fica um pouco deslocada. No desenho, que é quando geralmente uso cor, ela costuma ser mínima. Tons de terra, algo de verde e, algumas vezes vermelho. Não tenho muita afinidade com cores.

8 - Existem objetos específicos (no ateliê) que têm um significado importante para você?

[R.P.] Tem a prensa, na qual realizo a maior parte das minhas pesquisas. Neste caso é uma relação prático-afetiva.

9 - Você tem ferramentas que são exclusivas para o seu processo criativo?

[R.P.] Sim, tem algumas com as quais me dou melhor. No caso da gravura em linóleo ou da xilogravura, por exemplo, praticamente só uso faca e goiva V. Elas me permitem um embate maior com o material e gosto de sentir o corte. Não costumo usar outras ferramentas como os formões e as goivas em U, mesmo quando tenho uma área grande para desbastar. 10 10 - Você trabalha em uma obra de cada vez ou várias ao mesmo tempo? 


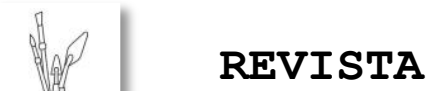 \\ APOTHEKE}

[R.P.] Trabalho vários projetos ao mesmo tempo porque um vai "puxando" o outro. Algumas ideias funcionam muito bem no desenho, outras só se revelam na gravura ou na instalação. Então, quando percebo que um trabalho esta nascendo dentro de outro, muitas vezes paro e início outra pesquisa, para não perder o momento. Depois, caminho com as duas concomitantemente.

11 - Você costuma limpar seu ateliê periodicamente, e qual o efeito disso sobre seu trabalho?

[R.P.] Limpo quando preciso, não tenho uma medida para isso. Às vezes, quando estou em pleno processo criativo não dá para ficar pensando em limpeza, vou até esgotar o trabalho, até resolver o que me mobiliza. Depois faço uma limpeza geral. Muitas vezes limpar o espaço é como finalizar de vez uma etapa, um projeto. A gente abre a área para receber novas pesquisas, novas inquietações.

12 - Quando você está pensando em seu trabalho, onde você costuma e gosta de ficar?

[R.P.] Em qualquer lugar. Não sou do tipo controlada. Às vezes a ideia de um bom trabalho surge de uma ida à 25 de março, aquela rua que vende de tudo aqui em São Paulo. Vejo algo e aquilo me traz a tona uma peça. Foi o que aconteceu no caso de um dos meus trabalhos, o dos bastidores, por exemplo. Às vezes é uma frase em um livro que me chama a atenção, uma música. Então, não tenho necessidade de estar em um lugar especial quando estou pensando no trabalho. Se estiver em uma lanchonete tomando um cafezinho consigo pensar no trabalho lá, sem problema. Às vezes penso na cama, antes de dormir, ou no sofá no ateliê também. 


\section{H) Revrsta \\ (A) APOHHEKE}

13 - Como é que você escolhe ou cria os títulos de seus trabalhos?

[R.P.] Alguns trabalhos são mais difíceis de pensar o título. Outros, surgem do título. Vejo um texto, uma frase, e aquilo me dá a ideia para a produção. Esta frase ou nome, que posso achar bonito, interessante, vira o título da obra. Quando isso acontece é normal que veja uma parte do trabalho já pronto ao ler aquilo que me provoca. Então o modo como dou título a um trabalho pode variar muito.

14 - Você tem assistentes?

[R.P.] Só para alguns projetos especiais. A necessidade de ter assistentes varia por conta de motivos como verba, necessidade de ter alguém especializado, ter que ficar sozinha para pensar melhor, gostar de trabalhar sozinha. Explico: nem sempre se tem verba o suficiente para ter um/uma assistente. Infelizmente é assim que funciona no Brasil. Outras vezes, quando se pensa um projeto já se visualiza a necessidade de alguém especializado. Foi o que aconteceu na instalação ASSENTAMENTO, por exemplo, ou na Bienal do Mercosul, com as TECELÃS. Existem alguns detalhes técnicos que eu não consigo resolver, preciso contratar alguém para isso. No caso na Bienal do Mercosul, por exemplo, tive duas assistentes que eram especialistas em massas cerâmicas e queima. Por recomendação de uma delas trabalhamos com o pessoal do SENAI de Santo André, um engenheiro químico especialista em massas cerâmicas para compor a massa que eu precisava e um especialista em moldes. O trabalho exigia esta mão de obra especializada.

Para o ASSENTAMENTO, tive que chamar um diretor de arte que também é fotógrafo, o Celso. Como a química fluiu super bem e ele estava interessado no projeto, além da quantidade de 


\section{(4)}

trabalho que tínhamos pela frente, acabamos por trabalhar juntos durante oito meses.

Neste momento estou com uma assistente, a Cláudia, porque o volume de trabalho é muito grande e temos prazo para uma exposição. Além disso ela é especializada em modelagem, costura, e estamos trabalhando nisto agora. Agiliza muito. Hoje em dia o artista tem que perceber que, dependendo de suas propostas e havendo verba, é fundamental a presença de outra(s) pessoa(s) no ateliê.

Mas tem vezes que é bom trabalhar sozinha também. Particularmente, sou do tipo solitária, não curto muito dividir ateliê por muito tempo. Gosto de trabalhar sozinha e mesmo que tivesse condições de contratar um/uma assistente integralmente não sei se o faria.

15 - Alguma vez você trabalhou com outro artista?

[R.P.] Sim, já trabalhei com outros artistas em ateliês coletivos, fora do país. Toda minha estadia em Londres, no London Print Studio, foi trabalhando coletivamente com outros artistas. E no Tamarind trabalhei com a Alison Saar e foi ótimo, aprendi muito. Produzimos uma gravura a quatro mãos no final. Já fiz outros trabalhos técnicos com outros artistas, como posteres, por exemplo. Mas no geral costumo trabalhar sozinha no meu ateliê.

16 - Como um artista, você tem um lema ou credo?

[R.P.] Um lema não, com certeza. Quanto a ter um credo, não sei se usaria essa palavra, que acho um pouco forte, mas acredito que todo trabalho sério, e não é só o trabalho dos artistas, deve ter comprometimento. E no caso da arte acho que cada um deve procurar sua verdade, sem modismos. O que serve para Maria não serve para Joana, então não sei como um/uma artista sério/a poderia ir atrás de modismos. É 


\section{Re RevssTa \\ A) APOPHEKE}

claro que cada período artístico tem suas preocupações, fatos históricos, técnicas e mídias que estão em evidência e que acabam contaminando, positiva ou negativamente, os trabalhos que são feitos naquele momento. É o caso da tecnologia hoje. Mas o uso ou a procura da tecnologia deve ser feita caso o trabalho exija. E existem muitos modos de se trabalhar com a tecnologia também. No caso dos já citados ASSENTAMENTO e TECELÃS isto era uma particularidade do trabalho, só dava para desenvolver a ideia apelando para a tecnologia. Agora, utilizar porque está na moda ou porque muita gente usa é estupidez. Se não vai acrescentar nada ao trabalho não use, pronto.

17 - Que conselho você daria a um jovem artista que está começando?

[R.P.] Que se preocupe com a sua verdade, com aquilo que o/a incomoda. Não entre em modismos, eles passam. Não tente se ater as verdades de outros, procure as suas. E tenha liberdade para criar. Pode parecer estranho esse último conselho para um/uma artista, mas tenho visto muitos/as jovens, principalmente nas universidades, que só leem um texto se ele for chancelado por um crítico, historiador de arte, filósofo ou sei lá qual profissional reconhecido no mundo das artes. E perdem um tempo imenso lendo aquilo para tentar enquadrar o trabalho em "fontes de referência respeitáveis". Mas se esquecem que boa música também é fonte de referência, poesia é uma ótima fonte de referência, um bom livro. O sul africano William Kentridge fez um trabalho belíssimo em cima do livro Memórias póstumas de Brás Cubas, do Machado de Assis. Quantos jovens artistas brasileiros fariam isto hoje em dia? Quantos leram Machado? Mas leem qualquer crítico obscuro que não tem nenhuma contribuição importante para fazer ao trabalho que 


\section{4) Revrsta (1) APOHARKE}

está sendo realizado, se este crítico estiver na moda. Tenho desenvolvido meus últimos trabalhos lendo livros sobre história, sociologia, biologia, arte e ciência. Muitas vezes a gente tem que procurar a própria bibliografia, fazer com que ela fundamente aquilo que está sendo pesquisado e não tentar encaixar nossa pesquisa em textos alheios aos nossos interesses. Isso é ilustração no mal sentido da palavra. Veja bem, não estou dizendo que não é preciso ler, estudar sobre a sua área, isso é essencial para qualquer profissional que queira desenvolver bem o seu trabalho. Mas um clássico da literatura é fundamental para qualquer pessoa que queira se desenvolver como ser humano. Procure ir além daquilo que é dado nas universidades, mas que você sinta que é necessário para o desenvolvimento da sua obra. Isso é fundamental para o desenvolvimento de uma poética.

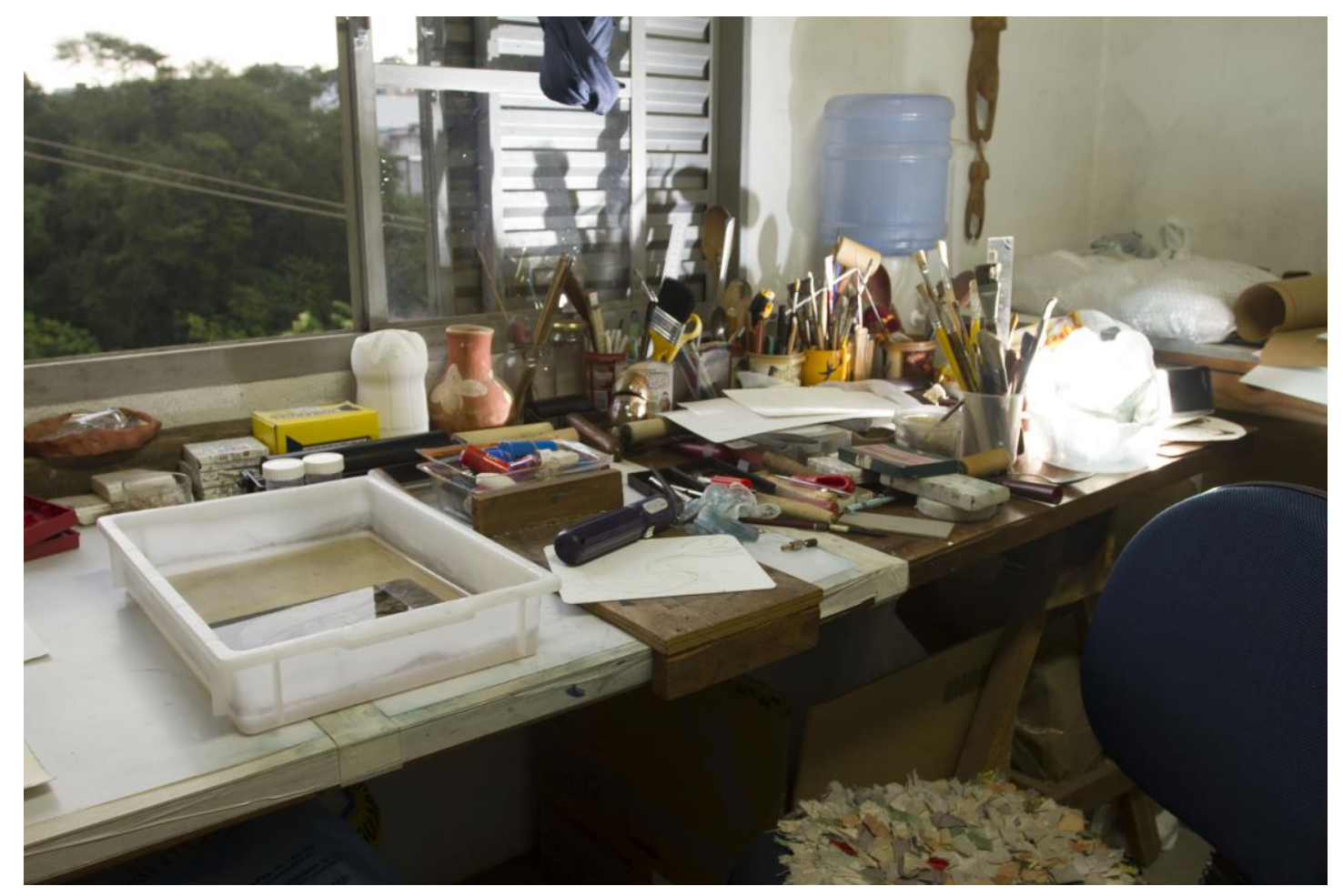

\footnotetext{
1 Extrato de entrevista realizado pelo Grupo de Estudos Estúdio de Pintura Apotheke (UDESC) - 2015. Imagens cedidas e de autoria da artista.
} 


\section{Rervysta A APOTHEKE}
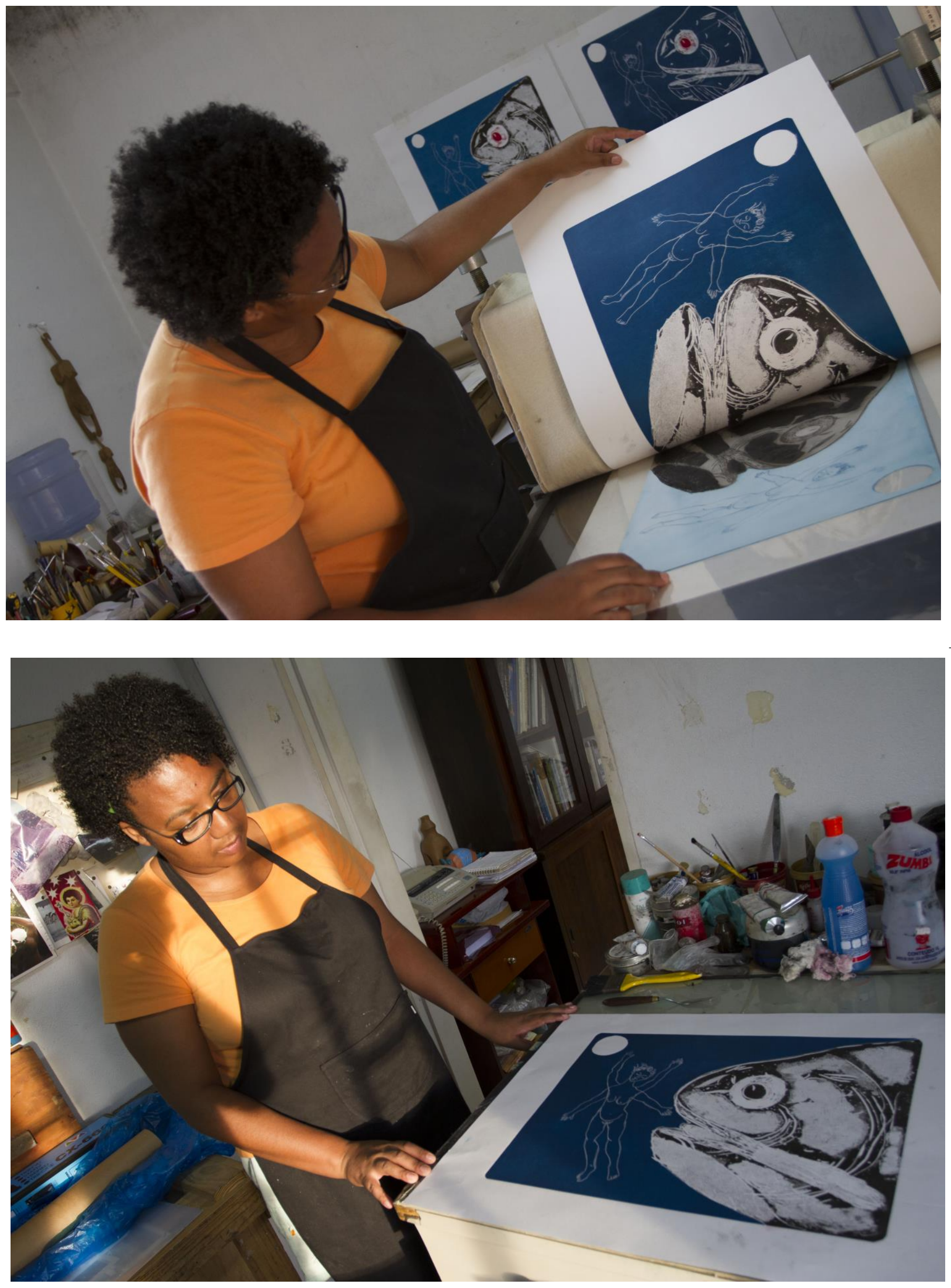

ISSN: 2447-1267 Santa Catarina, v.2, n.2, ano 2, fevereiro de 2016. 